\title{
Columbus' Egg? \\ Qualifications Frameworks, Sectoral Profiles and Degree Programme Profiles in Higher Education
}

\author{
Robert Wagenaar
}

\begin{abstract}
During the last 25 years international mobility has become paramount in higher education. International and national authorities and higher education institutions have set-up effective structures to facilitate and implement this process. It has become part of a higher education modernization process which obtained a serious push with the start and development of the Bologna Process in Europe as of 1999. However the same authorities have been far less active in finding answers on how to facilitate this process in terms of curriculum development, quality assurance and recognition. The initiative was largely left to individuals supported by their employing organizations. These have proven to be visionaries. Their efforts have led to competence and learning outcomes based descriptors for meta-qualifications frameworks and to important reference points / meta profiles for subject areas. Academics have been strongly involved in developing the latter and by doing so have offered a more sustainable basis for implementing reforms based on the student-centred approach, which is so relevant for today's world in terms of employability and citizenship. The most recent development has been the development of Tuning sectoral qualifications frameworks which allow for bridging the two European meta-frameworks, the EQF for Lifelong Learning and the QF for the European Higher Education Area, with sectoral and degree profiles. This can be seen as a breakthrough initiative because it offers us a transparent model which is developed and owned by academics and can easily be used by all involved in programme design and development, quality enhancement and assurance and recognition of (periods of) studies.
\end{abstract}

Keywords: qualifications frameworks; sectoral qualifications frameworks; sectoral profiles; degree programme profiles; reference points; learning outcomes; competences.

\section{Introduction}

During the last two decades the internationalization of higher education has really taken off with huge numbers of students experiencing cross border education, identifying and meeting their interests and needs in a global environment, as well as having an international experience. It might be seen on the one hand as a spin-off of the massification of Higher Education, which 
developed since the 1960s, and of the internationalization of the labour market on the other. In a relatively short period a non-structured form of free transnational movement of individuals has transferred into a well-structured industry. Probably there is no equal in the history of higher education where so many new jobs, based on new skills and competences, were created in such a short period, not only at institutional but also at national and international level. Academic staff, who, at first, played a central role in organizing student-mobility in and between cycles, was in no time replaced by 'real professionals'. The explosion in the numbers of students' mobility forced such a development, but there also followed the notion that 'overseas students' could be experienced as a very serious and in many cases crucial source of income: international students as a panacea for growth and budget balance. At the same time one may observe that mobility - although rewarding for individual institutions and countries - has very often been costly for the individual learner due to a lack of structures and related tools to accompany this process. It has been well documented that the internationalization of higher education has often prolonged the formal periods of study unnecessarily and that recognition of learning abroad had its serious flaws. This relates, for example, to the recognition of mobility periods but also to three and four-year bachelor programmes and the transfer from cycle to cycle. A recent report shows us that still at least one quarter of European students do not receive full credit for their studies taken abroad. ${ }^{1}$ Therefore the (academic) debate about the 'quality' of internationalization was paramount from its very start. ${ }^{2}$ It is, however, remarkable that this debate has not been related directly to the lack of involvement of academics and the professionalization of the internationalization agenda.

${ }^{1}$ Erasmus Student Network (ESN), "Problems of Recognition in Making Erasmus 2010 (Prime 2010). Final Report. Public Part," Brussels: Audiovisual \& Culture Executive Agency, Education and Culture DG, European Commission, 2011, http://eacea.ec.europa.eu/llp/ project_reports/documents/erasmus/accompanying_measures_2010/era_am_177245.pdf.

${ }^{2}$ Margarita Jeliazkova, and Don F. Westerheijden, "Systematic Adaptation to a Changing Environment: Towards a Next Generation of Quality Assurance Models," Higher Education 44, no. 3-4 (2002 ): 433-48; Jane Knight, and Hans de Wit, Quality and Internationalisation of Higher Education (Paris: OECD Publishing, 1999); Dirk Van Damme, "Internationalization and Quality Assurance: Towards Worldwide Accreditation?" Paper commissioned for the IAUP XIIth Triennial Conference, Brussels, 11-14 July 1999; Adinda van Gaalen, "Internationalisation and Quality Assurance, “ in EAIE Professional Development Series for International Educators, Volume 4, Amsterdam: European Association for International Education (EAIE), 2010; Marijk C. Van der Wende, and Don F. Westerheijden, "International Aspects of Quality Assurance with a Special Focus on European Higher Education," Quality in Higher Education 7, no. 3 (2001): 233-45; and Frans A. van Vught, and Don. F. Westerheijden, "Towards a General Model of Quality Assessment in Higher Education," Higher Education 28, no. 3 (1994): 355-71. 
The question posed here is whether qualifications frameworks, sectoral profiles or frameworks - besides degree programme profiles or reference points - are indispensable instruments for national and international higher education in the world of today? Are these Colombus' Egg to be used by content experts to facilitate recognition, programme design and delivery and quality assurance and quality enhancement? It is noticed in this respect that public authorities in general - although successfully responding to the growth of international education - have been slow in developing effective structures for organizing and guaranteeing the recognition of studies taken in another country and at another institution - both at degree level and in terms of mobility periods, at national as well as international level. This also applies to programme design and quality enhancement in Europe and in other regions in the world. This is actually an important observation, given the interest of countries in having a well-educated labour force, based on state of the art and officially recognized degrees taken at home or abroad. In practice, it were not so much public authorities but rather groups of individuals supported often by institutionalized organizations that took decisive initiatives to fill the gap. This article intends to show that this state of affairs had its advantages and its disadvantages. It will also be observed that much relevant work has been done by many, and that substantial progress has been made but in particular outside the formal structures by projects, etc.

This article concentrates on developments in Europe, because these have been a catalyst and stimulus for relevant initiatives elsewhere in the world. As stated, important steps have been made over time. Many organizations and initiatives played a role in this respect such as the Bologna Follow-up Group, the European Commission, ESIB/ESU, EUA and EURASHE, the Council of Europe, the ENIC-NARICS, ENQA, the Joint Quality Initiative (JQI) - initiator of the so-called Dublin Descriptors - and the Tuning Educational Structures in Europe project. It was the Tuning initiative, launched in 2000, which gave academics back their voice in the theatre of the modernization and internationalization of higher education by focusing on the content and role of education in realizing the Bologna Declaration.

Besides important initiatives at national level, such as the development of national qualifications frameworks in Ireland and Denmark, the Quality Assurance Agency benchmark statements in Britain, the Joint Quality Initiative (JQI), Tuning, EU Thematic Network Programmes (TNPs) and the European Commission should be singled out here, because they had the largest impact at structural level internationally, as will be discussed below. 'Structural level' means here the framing of higher education in its international perspective to facilitate recognition of degrees and periods of studies: the formulation of descriptors for the three cycles (bachelor, master 
and doctorate) and the associated degree or short cycle in HE, and the development of reference points at subject area level, which later gave birth to Meta Qualifications frameworks and - in the context of the Tuning initiative - Meta-Profiles and Sectoral Frameworks.

\section{Change of paradigm}

In retrospect, the years 2002 and 2003 can be seen as the most crucial years in the modernization and internationalization of European higher education. All major decisions and directions were taken and laid down in that period. A number of international 'Bologna seminars' took place during those years and most of all to the Berlin Communiqué, "Realizing the European Higher Education Area" (19 September 2003), in which both the development of an agreed set of standards, procedures and guidelines on quality assurance and the elaboration of an overarching framework of qualifications were included as means to create one European Higher Education Area. But even more crucial was the inclusion in the Communiqué of the paragraph: "Ministers encourage the member States to elaborate a framework of comparable and compatible qualifications for their higher education systems, which should seek to describe qualifications in terms of workload, level, learning outcomes, competences and profile"; 3 followed by "They also undertake to elaborate an overarching framework of qualifications for the European Higher Education Area", ${ }^{4}$ as well as a number of Bologna (related) conferences.

Within such frameworks, degrees should have different defined outcomes. First and second cycle degrees should have different orientations and various profiles in order to accommodate a diversity of individual, academic and labour market needs. First cycle degrees should give access, in the sense of the Lisbon Recognition Convention, to second cycle programmes. Second cycle degrees should give access to doctoral studies. ${ }^{5}$

By focusing explicitly on workload, level, learning outcomes, competences and profile, the ministers in practice announced a change of paradigm regarding the design and delivery of degree programmes. By including this statement, which in effect was inspired by the Tuning project, politics

${ }^{3}$ European Ministers for Higher Education, “ 'Realising the European Higher Education Area': Communiqué of the Conference of Ministers Responsible for Higher Education in Berlin on 19 September 2003 [Berlin Communiqué]," Berlin: Bologna-Berlin2003 Project Team, 2003, http://www.bologna-berlin2003.de/pdf/Communique1.pdf

${ }^{4}$ Ibid.

${ }^{5}$ Ibid. 
intervened clearly - probably without realizing it - in the prime responsibilities of higher education institutions and their teaching staff by making the switch from what should be learned, to how it should be learned. At that time the focus was still on teaching rather than on learning. Who had heard then of input versus output based teaching and learning or staff centred versus student oriented teaching and learning? For obvious reasons in the Communique a reference is made by the ministers to "welcome the commitment of Higher Education Institutions and students to the Bologna Process and recognise that it is ultimately the active participation of all partners in the Process that will ensure its long-term success." A crucial statement, which has proven mainly to be paying lip service in the years that followed. Only six years later in the Leuven / Louvain Communiqué a clear reference was made again to the important role of the higher education institutions and their staff in implementing the reforms. However, again the statement was not accommodated by a plan of action to link up with the higher education institutions. ${ }^{6}$

The Bologna follow-up group, which was installed to stimulate and monitor progress of the Bologna Process, never got directly in touch with initiatives to develop models/methodologies/ approaches to implement the very costly - change of paradigm announced in Berlin. Instead, it was the European Commission that decided to support a very relevant initiative from the academic world by co-financing the Tuning Educational Structures in Europe project and by inviting the TNPs (also co-financed by the EC) to take the Tuning approach on board. Other European networks, in particular Engineering, decided to go down that road independently. Officials of DG EAC, of which David Coyne and Peter van der Hijden should be singled out, were instrumental here. They, more than others involved in the process, saw the implications and potential of the Berlin Communiqué. This is remarkable given the fact that before the Berlin summit, two important Bologna seminars took place, which directed the steps set in Berlin by the ministers. The first one was named Working on the European Dimension of Quality (Amsterdam, March 12-13, 2002) and the second Qualifications Structures in European Higher Education (København, March 27 - 28, 2003).

The first one was an initiative of government officials of Flanders and the Netherlands, in particular of Marlies Leegwater and Noël Vercruysse. This

${ }^{6}$ European Ministers for Higher Education, "The Bologna Process 2020 - the European Higher Education Area in the New Decade: Communique of the Conference of European Ministers Responsible for Higher Education, Leuven and Louvain-La-Neuve, 28-29 April 2009 [Leuven Communiqué]," 2009, http://www.ond.vlaanderen.be/hogeronderwijs/bologna/ conference/documents/leuven_louvain-la-neuve_communiqu\%C3\%A9_april_2009.pdf. 
seminar fitted well in the discussion about quality management and quality assurance regarding national and international education which had developed since the beginning of the $1990^{\text {th }} .7$ This seminar was based on the work of an informal network which was initiated by individuals after the Prague Bologna summit in 2001, the so-called Joint Quality Initiative (JQI). This group consisted of individual government officials and representatives of quality assurance organisations, mainly from the Northern part of Europe. The JQI was originally intended to be a network focusing on quality assurance and accreditation in relation to the bachelor and master programmes in Europe. At a later stage it also covered the short cycle or associated degree and the doctorate. Its contribution is the definition of descriptors for the higher education cycles, which became known as the Dublin Descriptors. These were developed between 2001 and 2004 and were somewhat later used as the basis for the Qualifications Framework for the EHEA which was endorsed by the ministers of education in 2005 at the Bergen Bologna summit. The importance of this initiative cannot be stressed enough. The initiators understood perfectly well that a systematic approach was the only way forward to make 'Bologna' successful. But by phrasing the descriptors in terms of expected/required outcomes the group revolutionised the discussion about the modernization of higher education in Europe. In practice they transferred a debate, which had slowly developed in a number of northern European countries, into a European one.

This is no different from another initiatives which was taken by a group of universities in close cooperation with the European Commission in the autumn of 2000, the Tuning Educational Structures in Europe project. Immediately after the Bologna Declaration was signed, a group of ECTS experts developed the idea that Bologna would not work without a radical change of concept regarding the design and delivery of degree programmes. It was concluded that ECTS had reached its limitations by focusing on

${ }^{7}$ Carolyn Campbell, and Marijk van der Wende, "International Initiatives and Trends in Quality Assurance for European Higher Education. Exploratory Trend Report," Helsinki: European Network for Quality Assurance in Higher Education, 2000, http://www.enqa.eu/files/ initiatives.pdf; Lee Harvey, and Diana Green, "Defining Quality," Assessment \& Evaluation in Higher Education 18, no. 1 (1993): 9-34; Dirk Van Damme, "Trends and Models in International Quality Assurance and Accreditation in Higher Education in Relation to Trade in Education Services," a paper presented at the OECD / US Forum on Trade in Educational Services, Washington, D.C., 23-24 May 2002, http://www.unizg.hr/fileadmin/upravljanjekvalitetom/ pdf/docsmjernice/oecd_trends_and_models.pdf; and Frans A. van Vught, and Don. F. Westerheijden, Quality Management and Quality Assurance in European Higher Education: Methods and Mechanisms (Luxembourg: Office for Official Publications of the Commission of the European Communities, 1993). 
student workload only. Using a credit system in itself was already a major step forward in making degree programmes more transparent and flexible, but it became clear over the years that recognition of periods of studies in terms of both transfer and accumulation would never work when the level of competence that is developed in the process is not paramount. It was also concluded that the use of cycles requires not only the redesigning of degrees, but also - preferably internationally - agreed reference points for subject areas. The necessity of points of reference was also understood in the UK, where the Quality Assurance Agency started in those years its policy of developing subject benchmark statements of which the first were published in 2002. They have proven to be of great value not only for UK higher education but also for Europe as a whole. ${ }^{8}$ By focusing on the outcomes of the teaching and learning process, the focus shifts from the teacher/professor as the main source of knowledge to the student as the focal point. No longer should the transfer of knowledge be central in the learning process but the shaping of a graduate who would be able to take up his or her role in society immediately after graduation on the basis of the competences required. For that reason the Dublin descriptors distinguish different types of outcomes, phrased in terms of competence development. In accordance with the same line of thinking, in Tuning the focus is on transferable or generic competences besides subject specific ones.

\section{Amsterdam consensus}

At the Amsterdam Bologna seminar of March 2002 it was concluded that general descriptors for the different cycles and reference points at subject area level should go hand in hand. Its conclusion was far reaching in directing the Bologna Process:

There is a widely-shared consensus that the 'Dublin Descriptors', defining key outcomes for Bachelors and Masters programmes in general (...) are useful. These generic descriptors are complementary to the more specific outcomes of the Tuning project (...), which have been developed at the level of areas of knowledge ('disciplines') In other words, the 'Dublin Descriptors' need to be 'tuned'. Moreover, Tuning project outcomes are not to be taken as prescriptive. In that respect, it should be remembered that outcomes do not define curricula. (...) The approach to quality building on a combination of the 'Dublin Descriptors' and Tuning project outcomes

\footnotetext{
${ }^{8}$ Quality Assurance Agency for Higher Education (QAA), http://www.qaa.ac.uk/.
} 
apply to 'traditional' delivery of higher education as well as to transnational education, distance education, etc. ${ }^{9}$

It was also concluded at the conference that "Gains from the Tuning project further include that there is a broader than expected consensus among European higher education institutions on descriptors of their programmes, starting from outcomes rather than starting from curriculum inputs and elements. At the same time, there is less than expected diversity regarding length/credits of programmes." We will come back to these statements below.

It is worth noting that related to the above, an important discussion arose in Amsterdam about the relative value of programme versus institutional approaches to quality assurance:

Both are important, was the general view. The 'Dublin Descriptors' as well as the Tuning project outcomes are directed primarily at programme level approaches. Many, including expressly the student representatives, gave programme level quality assessment as the priority for public policy, inter alia because this would give more direct assurance of quality ('consumer protection'). Institutional quality assurance was mostly seen as the responsibility of autonomous, well-managed higher education institutions, even though some participants voiced the opinion that with 'mass' or 'universal' higher education, and in the emerging network society, such coherent higher education institutions will become ever rarer. ${ }^{10}$

\section{Qualifications framework for the EHEA}

Twelve months later, in 2003, at the Bologna seminar Qualifications Structures in European Higher Education, the discussion continued. At this conference the role of the JQI and Tuning were again highlighted, this time explicitly in relation to the development of a European and National Qualifications Frameworks. The rapporteur of the conference Sjur Bergen, Council of Europe, stipulated correctly that all higher education systems at the time already have their 'qualifications framework' but that these are (mainly if not only) based on input factors and formal characteristics. The innovation to be realized was basing such frameworks on the learning outcomes of the educational process. In his words: "A national qualifications

${ }^{9}$ Don F. Westerheyden, and Marlies Leegwater, "Working on the European Dimension of Quality. Report of the Conference on Quality Assurance in Higher Education as Part of the Bologna Process, Amsterdam, 12-13 March 2002" (Zoetermeer: Ministry of Education, Culture and Sciences, 2003), 97-98.

${ }^{10}$ Westerheyden and Leegwater, "Working on the European Dimension of Quality,": 98. 
framework is simply a systematic description of an education system's qualifications where all learning achievements are measured and related to each other. A European qualifications framework would amount to an agreement about a common structure or architecture within which different national qualifications could be located". The conference agreed upon a number of important recommendations for the Berlin summit of ministers of education. The most relevant ones are listed here for this article:

1. At each appropriate level, qualifications frameworks should seek to describe the qualifications making up the framework in terms of workload, level, quality, learning outcomes and profile. An EHEA framework should seek to describe qualifications in generic terms (e.g. as first or second cycle degrees) rather than in terms specific to one or more national systems (e.g. Bachelor or Master);

2. Qualifications frameworks should also seek to describe these qualifications with reference to the objectives or purposes for higher education, in particular with regard to four major purposes of higher education: preparation for the labour market, preparation for life as active citizens in democratic society, personal development and development and maintenance of an advanced knowledge base;

3. Within the overall rules of the qualifications frameworks, individual institutions should have considerable freedom in the design of their programmes. National qualifications frameworks, as well as an EHEA framework, should be designed so as to assist higher education institutions in their curriculum development and design of study programmes. Qualifications frameworks should facilitate the inclusion of interdisciplinary higher education study programmes. ${ }^{11}$

The reader will have noticed that in the Berlin Communiqué quality as a descriptor is replaced by competences. This is done for an obvious reason, namely that quality does not fit in this context, as being an indicator which encompasses all others.

\section{Contribution of Tuning}

From the day the Bologna Declaration was signed, a fear was expressed that the Bologna Process would lead to the harmonization of higher education

11 "Bologna Seminar on Qualification Structures in Higher Education in Europe. Recommendations," Copenhagen: Bologna-Berlin2003 Project Team, 2003, http://www. bologna-berlin2003.de/pdf/Results_copenhagen.pdf. 
programmes. This was in particular voiced by higher education institutions and (their) academics. Bologna being a governmental process this fear was real, as was also stated by higher education experts like Dirk van Damme. ${ }^{12}$ It was another reason for the group of ECTS experts to develop Tuning. Clearly related to the first argument, mentioned before, that the focus in higher education should switch to the outcomes of the learning process as well as to the learner. In the opinion of the Tuning initiators educational structures, degree programmes and the actual teaching and learning process should be the prime responsibility of higher education institutions and their staff. The basic thought was that higher education programmes should allow for diversity, flexibility and individual learning pathways, with full respect for consistency, level and quality. Moreover, the process of re-designing curricula should lead to programmes which would better match the requirements of the labour market and society. The name Tuning was chosen to express its goal to look for common ground, reference points, which allow for and stimulate profiling of individual degree programmes. For that reason a ten-step approach was developed for designing new programmes and redesigning and enhancing existing ones. The first three steps are of particular relevance here: 1 . determine the need for and potential of the degree programme by consulting stakeholders and deciding whether the programme proposed will satisfy actual professional and/or social demands; 2 define the profile and key programme competences of the programme by defining the body of knowledge, the focus and orientation, identifying the employment sectors and its contribution to developing citizenship and personal culture; 3 . formulation of the programme learning outcomes. The full ten-step approach is included in the publication A Tuning Guide to Formulate Degree Programme Profiles..$^{13}$

\section{Reference points - Degree programme Profiles}

A condition for profiling of degree programmes is that there should be an agreed (preferably internationally) reference framework available that consists of sets of common points of reference. These frameworks are important as a means to decide whether a degree programme meets the minimum quality standards and therefore deserves to be accredited. Reference

${ }^{12}$ Dirk Van Damme, "European Quality Assurance: Development and Challenges," Brussels: Steering Committee of Tuning Project, 2001.

13 Jenneke Lokhoff et al., eds., A Tuning Guide to Formulating Degree Programme Profiles (Bilbao, Groningen, and The Hague: University of Deusto, 2010). 
points make provision for diversity, freedom/flexibility and autonomy, and allow higher education institutions to focus on their mission, position and role in the higher education environment. While some universities want to position themselves as international players, other may prefer to focus on their national and/or regional and/or local role. Also being research or more applied in orientation is of relevance. From 2007, Tuning published its Reference Points for the Design and Delivery of Degree Programmes. ${ }^{14}$ Provisional documents were published in 2005. Many Thematic Network Programmes also published their Tuning reference points, sometimes within the framework of Tuning, sometimes on their own, but always according to an agreed common format. This format was published in 2005 and contains 6 items: 1. Introduction to the subject area; 2. Degree profile(s); 3. Learning outcomes \& Competences - level cycle descriptors; 4 Workload and ECTS; 5. Learning, Teaching and Assessment; and 6. Quality enhancement. Item 2 includes both information about typical degrees offered in the subject area as well as typical occupations held by the graduates in the subject area. These reference-points brochures were validated by committees of independent peers in 2007. The way in which these reference points within the Tuning context were (further) developed and agreed, is explained in detail in the contribution of Julia González in this volume of the Tuning Journal.

The Tuning reference points are based on the distinction between generic or transferable competences and subject specific ones. As is well known, Tuning uses competences in an all- encompassing way, covering knowledge, skills and wider competences as abilities, responsibilities, and attitudes. Tuning highlights the use of generic competences because of its relevance for society, both in terms of employment and citizenship. In its European stakeholders' consultations in 2001 and in 2008 the relevance of this approach was confirmed. The outcomes of consultations in other regions of the world lead to comparable outcomes.

In 2008, consultation based on 7087 responses, well spread over four stakeholder groups, academics, employers, graduates and students, four competences are ranked highest by all of them:

- Ability for abstract and analytical thinking, and synthesis of ideas

- Ability to apply knowledge in practical situations

- Knowledge and understanding of the subject area and understanding the profession

- Ability to identify, pose and resolve problems

${ }_{14}$ Tuning Educational Structures in Europe (Tuning Europe), http://www.unideusto.org/ tuningeu/. 
Academics and graduates ranked Ability to learn and stay up-to-date with learning as number five, while employers and students ranked Ability to work in teams as the fifth important competence. Also the ability to communicate both orally and through the written word in first language was thought being very important, although it was ranked lower.

This outcome is relevant when compared to the Dublin descriptors as included in the Qualifications Framework for the EHEA: Knowledge and understanding, Applying knowledge and understanding, Making judgments, Communication skills and Learning skills. It shows that the Tuning approach can easily be related to the structure of the QF for the EHEA. It also underlines that the descriptors as developed by the JQI are sensitive ones and that these are indeed complementary to the Tuning approach, both in terms of level descriptors and reference points. Together, they should therefore be applied at degree programme level. This is also what is happening in practice, although - depending on the country involved - it has proved to be a slow process.

\section{European Qualifications Framework for Lifelong Learning}

When the QF for the EHEA was endorsed at the Bologna summit of ministers in Bergen in 2005, the European Commission had already taken the initiative to develop a Qualifications Framework for Lifelong Learning (EQF for LLL), to combine the outcomes of the Bologna Process and the Copenhagen Process for Vocational, Education and Training (VET) launched in 2002. Experts from both the Higher Education sector and the VET sector were involved in designing this framework, although the VET sector was the prime authority in the process. This was probably due to the fact that the HE sector already had its own Qualifications Framework. After intense discussions it was agreed to make a distinction between three types of descriptors: knowledge, skills and wider competences. While the QF for EHEA has stand-alone descriptors, it was decided that the EQF for LLL descriptors would have a structure of 8 levels and be cumulative, where a level builds on the previous level. In 2008 the European Parliament and the Council of Ministers passed its Recommendation on the establishment of an $E Q F$ for $L L L$. The member states were invited to create their National QF based on the EQF features, and sectors were called upon to develop Sectoral Qualifications Frameworks. This challenge was taken up by Tuning in 2008. It had numerous reasons to do so.

But before linking this development to Tuning, it is important to have a closer look at the definitions of skills and competences being used in the EQF 
for LLL. "Skills" means in EQF terms "the ability to apply knowledge and use know-how to complete tasks and solve problems. Skills are described as cognitive (involving the use of logical, intuitive and creative thinking) or practical (involving manual dexterity and the use of methods, materials, tools and instruments)." By "Competence" is meant "the proven ability to use knowledge, skills and personal, social and/or methodological abilities, in work or study situations and in professional and personal development." However, it is added that in the context of the European Qualifications Framework, competence is described in terms of responsibility and autonomy. As in the case of Tuning - an encompassing definition of competences is used. It is, however, problematic that in the final version the EAC decided to remove 'wider' as a crucial addition to the label descriptor 'competence'. By doing so it created a contradiction in terms. This is confirmed by Mike Coles, the main author of the framework, in 2012. It is also contrary to other European Commission actions where the notion of key competences is flagged. For example the European Framework of Key Competences for Lifelong Learning adopted in 2006: "It identifies and defines the key abilities and knowledge that everyone needs in order to achieve employment, personal fulfilment, social inclusion and active citizenship in today's rapidlychanging world." It is no wonder that the EQF initially lead to confusion in particular in the higher education sector.

\section{Tuning Sectoral Qualifications frameworks or profiles}

Although the Bologna Follow-Up Group concludes after comparing the two systems that these are compatible, in reality this is not quite true. Not only is the QF for the EHEA ECTS-credit based and the other one is not, it is also constructed on the basis of a different philosophy. The Tuning experts' group is now faced with a number of issues: two competing frameworks for the Higher education sector, one based on stand-alone descriptors and the other one on cumulative descriptors and the challenge to bridge the two meta-qualifications frameworks and the Tuning reference points or metaprofiles at subject area level. From this challenge the idea was born that a solution might be found in developing sectoral qualifications frameworks as an intermediate between the subject area level and the meta-level. This requires a grouping of academic programmes in terms of domains or sectors. A sector or domain is understood here as a combination of related fields of study which are based on more or less comparable learning profiles. Not surprisingly five to six sectors are distinguished: Humanities and the Creative and Performing Disciplines, Engineering, Natural Sciences, Health Care and 
Social Sciences. The order used here is based on the mutual relationship between the sectors and can be visualized as follows:

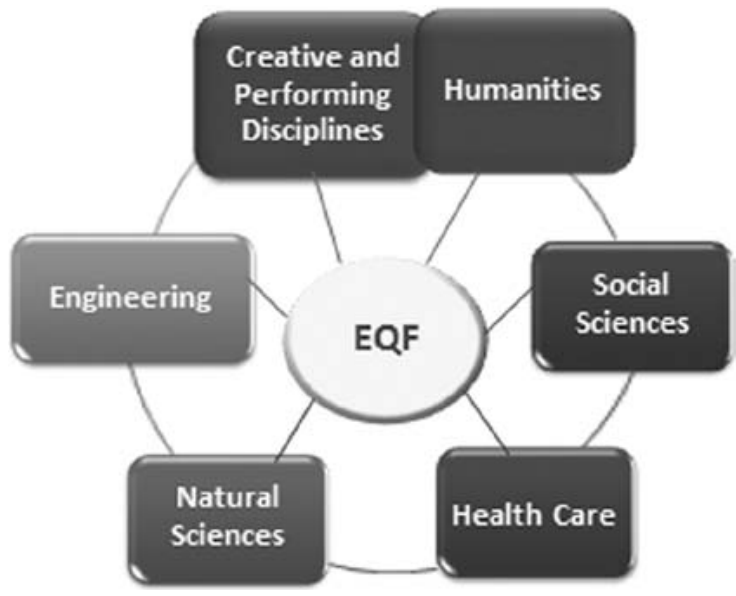

From 2008 to 2010 a first project was implemented, to develop a Tuning SQF for the Social Sciences. In the project the sector is represented by the following subject areas: Business Studies, European Studies, Education Sciences, Occupational Therapy and Social Work, Law, Psychology and International Relations. The project designed a framework which not only covered the higher education sector, that is the levels 5 to 8 of the EQF, but also the levels 3 and 4 (being the entrance level to higher education). This framework can be seen as being pioneering and innovative, but most of all a major step forward to bridge the different initiatives so far. The approach of developing the framework by using the strategy of reflection, debate and consultation is well described in the final report of the project. The project itself highlights the fact that it struggled (initially) with the division between skills and (wider) competences. This is reflected in its outcomes. We will come back to this.

The project as such is daring. Not only would it combine the reference points which were prepared for the different subject areas during a painstaking process, it also would relate them to the principles of the EQF for LLL with full respect for the Descriptors of the QF for the EHEA. The outcome of this process was twofold: a definition of a short profile for the sector and the aligned matrixes of expected levels of achievement - based on the three EQF descriptors knowledge, skills and wider competences - defined for each level.

The well-formulated profile offers insight in what the sector stands for and how it distinguishes itself from other sectors: 
The social sciences are concerned with the study of and the provision of services to society as articulated in individuals, groups and communities. They examine social structures and organizations (economic, legal, cultural, religious, political, etc.) in both space and time. They explore the dynamic processes and inter-relationships between them and how different meanings and attitudes are created and have to be negotiated. Their scope ranges from the minutiae of human behaviour and development to largescale social movements. Social Sciences have a strong ethical dimension related to social justice, wellbeing, cohesion and citizenship. ${ }^{15}$

The profile as such shows the potential of this approach. When Tuning developed the sectoral philosophy - as a preparation for SQF-projects - it assumed that students move mostly within one sector or between two related sectors. This implies that recognition issues are also relating to this scope. As an example the subject area of History might serve well. Positioned in Humanities it has clear relations with Social Sciences and vice versa. This is reflected in the matrixes of learning outcomes for the different levels which not only offer reference points for the disciplines covered by the SQF for Social Sciences, but also for related academic fields. However, there is a weakness in the approach taken by the Social Sciences SQF project. It kept close to the cumulative approach of the EQF for LLL. One of the consequences of this is that the learning outcomes statements at level 7 must be read in in conjunction with those defined for the levels 5 and 6 . A result of this approach was that learning outcomes statements for the descriptors of wider competences at level 8 were not thought necessary, because they were already covered by lower levels. An issue here is that the learning outcomes identified for the levels 7 and 8 covering knowledge and skills are phrased in a rather open way, and require that the expected achievement levels 5 and 6 are taken into account as well in order to understand what is actually covered in hard fact. By linking different types of knowledge and awareness to neutral phrases like 'a specialist area or specific field of study or practice' they can be used for every sector independent of the discipline / field of study covered. This seems unavoidable in this set up because at those levels the sector tends to encompass a wide range of specializations taught, learned and assessed in the many academic fields covered.

The key problem with cumulative descriptors which define expected levels of performance is that this approach makes the process of recognition of periods of studies based on the competences obtained and the learning outcomes achieved a very complex one and, therefore, it becomes the work

15 Tuning Europe, "Tuning SQF for the Social Sciences," http://www.unideusto.org/ tuningeu/tuning-sqf-social-sciences.html. 
of specialists. They are simply too difficult to handle and therefore to apply. This implies that academics, although expected to develop and to work with competence statements and programme and module learning outcomes, are not well served when it comes to the recognition of learning. This is not beneficial because, in the last resort, Boards of Examiners that consist of academics and individual professors usually have the final say in matters of recognition at institutions. Therefore, it is of crucial importance that the instruments which facilitate (inter)national mobility and recognition are owned by the academic staff and used on a daily basis. It seems to be the only reasonable way to convince academics to develop an open mind regarding learning that has been obtained elsewhere. Tuning and Thematic Networks have shown us that trust and confidence is strengthened considerably when academics have a chance to learn to appreciate each other in open dialogue about their field of study.

This was strongly kept in mind when in 2010 the Tuning SQF HUMART project took over the banner from the Tuning SQF Social Sciences project. HUMART stands for Humanities and the Performing and Creative Arts. Although it was realized when defining the project that the definition of Humanities commonly includes visual and performing arts, based on experience so far, it was thought that it might not be feasible and helpful to include subject areas involved in a single framework. Therefore, the option was kept open to develop two frameworks, one for the Humanities and one for the Performing and Creative Disciplines.

The main objective of HUMART was largely comparable to the one of the Social Sciences: to develop an easily readable SQF framework which would be defined and owned by academics. It should be consistent and be based on stand-alone descriptors in order to bridge the two existing European meta-frameworks. A three-step approach was applied. A first step was to rephrase and re-order the existing sets of the subject area descriptors for the Bologna three cycles on the basis of the EQF for LLL. This applied to history, visual and performing arts and architecture. Music - also involved - had already made this step at an earlier stage. For Literary Studies, Linguistics, Art History and Theology and Religious Studies reference points were still to be developed at European level. A second step was to compare the descriptors of the subject areas involved. This comparison formed the basis of the final step: to design and define the sectoral qualifications framework. When the second phase was applied, it became clear that on the basis of comparison it was greatly preferable to develop two frameworks instead of just one. Two autonomous frameworks would do more justice to the character of the two specific sets of subject areas and would therefore be a far better tool for the design and implementation of degree programmes, 
including quality assurance and enhancement, as well as the recognition of periods of studies, than a single framework.

The Tuning experts in visual arts, theatre, music and architecture proved this point by defining the following profile for their academic fields:

The Creative and Performing Disciplines encompass a range of fields of an artistic and technical nature in which creativity, interpretation and aesthetic judgment are paramount. These disciplines involve the invention and generation of ideas, forms, images, sounds, structures, performances and texts, which can be used in experimental development to produce new artefacts, spaces, devices, products or processes. The joint concept of a unified sector radiates a stronger focus upon this innovative potential, which is often insufficiently highlighted when considering the constituent disciplines in isolation. The Creative and Performing Disciplines contribute to the experience of life in ways that complement, and have parity with, the contributions of science, technology and philosophy. They have the capacity to persuade, subvert, celebrate and confront traditions; to act as powerful cultural agents; to establish individual aspirations, to help people learn to appreciate differences and to construct coherent value systems. The ideas, methods and priorities of the Creative and Performing Disciplines constitute a distinct network of knowledge, using its own language and procedures, which functions in order to describe, understand and engage in different forms of experience. This network of knowledge also develops distinct notions of artistic and other forms of research, in particular those where visual experience, creating, performing and making form part of the research process itself. ${ }^{16}$

This profile shows clearly the peculiarities of the sector within the much wider domain of the Humanities. The framework itself is described by the experts involved as "a bold attempt to produce a common set of statements about expected achievement levels for students in any and all of the disciplines represented: the visual arts, the performing arts, music and architecture". However, much more important is the breakthrough approach that is developed and applied. Inspired by the expert group of Architecture the sector managed to find a common focus and by doing so set itself apart from other sectors. As core characteristic for the sector was identified "Creation \& Creativity", which was supported by seven dimensions which offer further identification/specification. The implication of using a core characteristic and dimensions is twofold: it not only strengthened the identity of the higher arts educational sector in Europe, it also highlighted the innovative potential

16 Tuning Europe, Tuning Sectoral Qualifications Frameworks for the Humanities and the Arts. Final Report 2010 - 2011 [SQF HUMART Final Report 2010-201] (Bilbao: University of Deusto, 2012). 
of the sector. This not only underlined the importance of the sectoral approach in terms of recognition of studies, curriculum development and quality assurance and enhancement but also its capability to act as a coordinated force in more political terms.

This approach was also used by the Humanities disciplines to construct their sectoral qualifications framework. For the Humanities for obvious reasons "humanness in culture and society" was identified as its core characteristic or focal point. It was related to 8 dimensions, one more than in the case of the performing and creative disciplines. These dimensions were linked closely to those of the Performing and Creative Disciplines, being a related domain. In the grid below both sets of dimensions are offered. It shows that the central 'values' of each of the sectors are expressed in key terms. Having been drawn up by academics in these sectors, these terms will be recognized by their academic colleagues.

\section{Table 1}

SQF Dimensions

\begin{tabular}{|l|l|l|l|l|}
\hline \multicolumn{1}{|c|}{$\begin{array}{c}\text { Humanities } \\
\text { Dimensions }\end{array}$} & \multicolumn{1}{|c|}{$\begin{array}{c}\text { Creative and Performing } \\
\text { Disciplines dimensions }\end{array}$} & Knowledge & Skills & $\begin{array}{c}\text { Wider } \\
\text { competences }\end{array}$ \\
\hline The Human Being & $\begin{array}{l}\text { Making, Performing, } \\
\text { Designing, Conceptualising }\end{array}$ & & \\
\hline $\begin{array}{l}\text { Cultures and } \\
\text { Societies }\end{array}$ & $\begin{array}{l}\text { Re-thinking, Considering and } \\
\text { interpreting the Human }\end{array}$ & & & \\
\hline $\begin{array}{l}\text { Texts and } \\
\text { Contexts }\end{array}$ & $\begin{array}{l}\text { Experimenting, innovating \& } \\
\text { Researching }\end{array}$ & & & \\
\hline $\begin{array}{l}\text { Theories and } \\
\text { Concepts }\end{array}$ & $\begin{array}{l}\text { Theories, Histories and } \\
\text { Cultures }\end{array}$ & $\begin{array}{l}\text { Technical, environmental and } \\
\text { Contextual issues }\end{array}$ & & \\
\hline $\begin{array}{l}\text { Interdisciplinarity } \\
\text { Communication, Collaboration }\end{array}$ & & & \\
\hline Communication & Initiative \& Enterprise & & \\
\hline $\begin{array}{l}\text { Initiative and } \\
\text { Creativity }\end{array}$ & $\begin{array}{l}\text { Professional } \\
\text { Development }\end{array}$ & & & \\
\hline
\end{tabular}

To show how this approach works, the first two dimensions which are typical for each of the two sectors, Creative and Performing Disciplines (CPD) and Humanities (HUM) at level 6 are highlighted. 


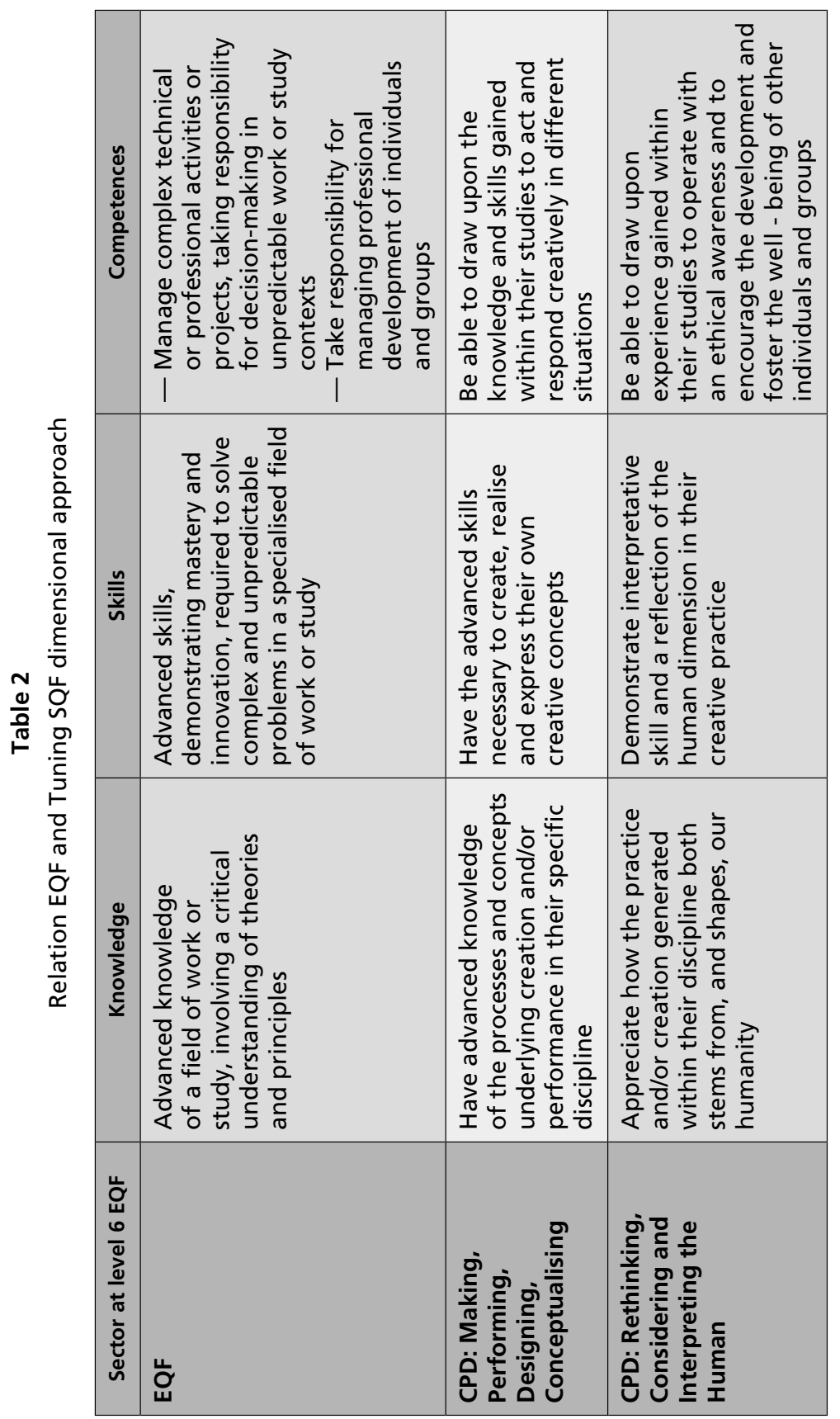




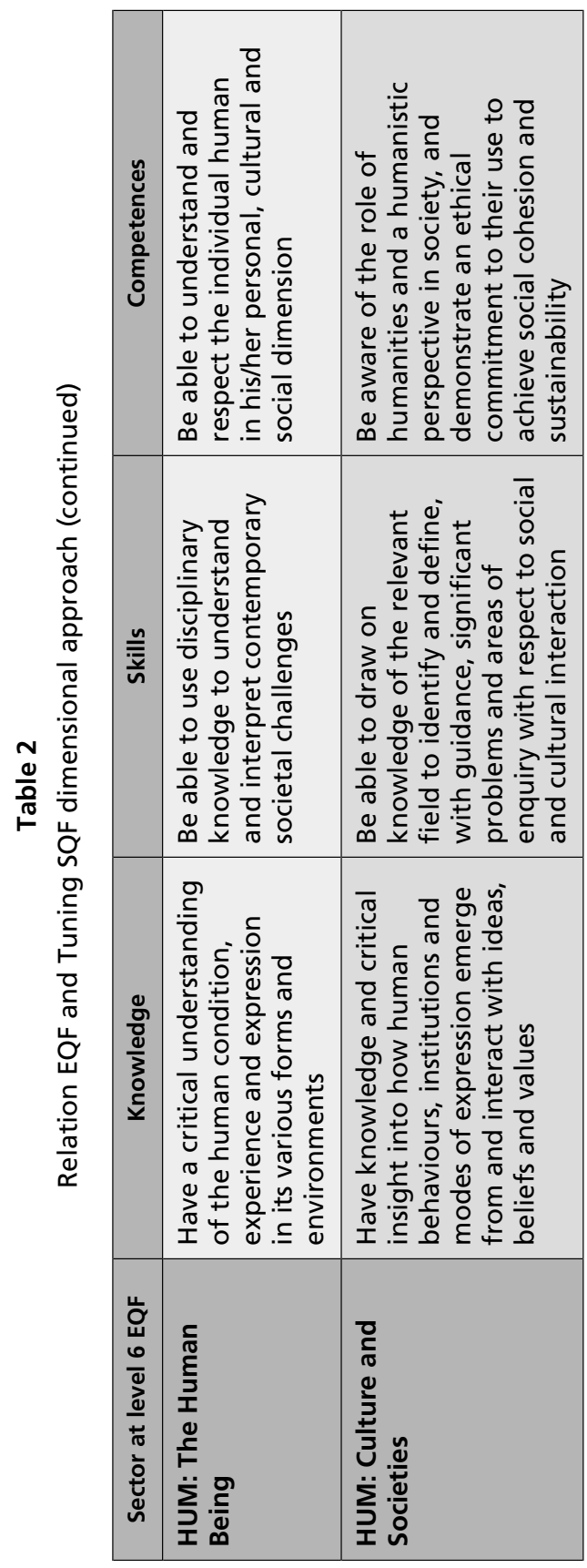


In both SQFs the EQF definitions of knowledge, skills and (wider) competences have been followed. In the case of (wider) competences the emphasis has not been explicitly put on personal responsibility and autonomy. One feels the tension between the EQF expressions as managing and decision making, which are more operational than the SQF expressions which focus much more on taking social responsibility and offer guidance. It shows how difficult it is to use these descriptors in a one dimensional way.

From the scheme above it can be learned that although the two sectors are related, the expected achievements in terms of learning outcomes can be clearly distinguished. This is even truer when these would be compared to other sectors. It shows the advantages of a systematic approach. It can be observed that a sectoral qualifications framework has a real added value when the following conditions are met:

The SQF is:

- identified by the academics working in the sector as being the core of their sector and academic field

- based on a distinctive profile and dimensions which grasp the core characteristic of the sector and its underlying disciplines

- based on expected levels of achievement / Learning Outcomes which are formulated as stand-alone descriptors

- preferably limited in size to one page for each level

- formulated in such a way that the descriptors are clear, transparent and easy to read

- formulated in such a way that the expected levels of achievement of each discipline covered by the framework can be phrased according to the dimensions identified for the sector

These requirements seem to be met by the two SQF's discussed here. They also allow for learning which has been obtained in an informal or nonformal context. In cases of an interdisciplinary programme it might be necessary to take the two related frameworks into account to position the programme in its academic environment.

A next step should be the alignment of meta-profiles or reference points at subject area level to the related sectoral ones. Architecture, music, visual and performing arts have already gone through that process successfully. One can conclude that this has led to better, more precise, reference points than we had until now. This is of relevance again for external quality reviews and degree programme enhancement. 


\section{Bridging the QF for EHEA and the EQF for LLL}

Both European Meta Qualifications Frameworks are one dimensional. In the case of the QF of EHEA it was built on the descriptors range Knowledge and understanding, Applying Knowledge and understanding, Judgment, Communication and Learning skills. In the case of the EQF for LLL on the descriptors Knowledge, Skills, (Wider) Competences. This is a strength, but also a weakness. The danger is that it simplifies reality and has therefore a limited meaning and value. The basic idea of a Qualifications Framework is that it sets expected levels which should be met, by offering a fair description of the sector/academic field. Therefore, the described SQFs of the Creative and Performing Disciplines and of the Humanities, which are based on dimensions is very promising. Such an SQF seems to do more justice to the particular features of each sector and the subject areas it contains. The reason for this is that such a framework is two dimensional and offers much more possibilities for deepening the features. This in turn offers better opportunities for measuring the expected level of competences / learning outcomes. The beauty of having two axes or legs is that it offers a clear structure, without being mechanic.

However, does it actually offer a reliable and feasible answer to the issue of having two competing frameworks for higher education? It seems it does. To demonstrate this, we take the two SQFs with the identified 7 and 8 dimensions as a starting point. To make it fit, it is required to re-arrange these dimensions slightly. Also an $8^{\text {th }}$ descriptor is added to the SQF for Performing and Creative Disciplines: professional development. This seems to be an element lacking in the original scheme. It is also necessary to move the second descriptor of the QF for the EHEA 'applying knowledge and understanding to the horizontal axis because it equals the EQF descriptor for skills. We use the $2^{\text {nd }}$ cycle descriptors of the QF of EHEA to illustrate the model, which is the outcome of the modifications mentioned. The modifications are minor ones.

Table 3 shows that it is not at all over complicated to order the dimensions of the two Tuning SQFs according to the five descriptors of the QF for the $2^{\text {nd }}$ cycle of the EHEA. As will be noticed the first special feature or dimension which offers the SQF its unique character has been positioned as a separate descriptor, because it stands out from the other ones as a core characteristic which does not fit into the categories used in the QF for EHEA. The other categories can easily be related to this meta-framework. It shows the usefulness of further differentiation in dimensions within the broader QF descriptors. This applies in particular for descriptor 1 - Knowledge and Understanding and descriptor 3 - Judgement. 


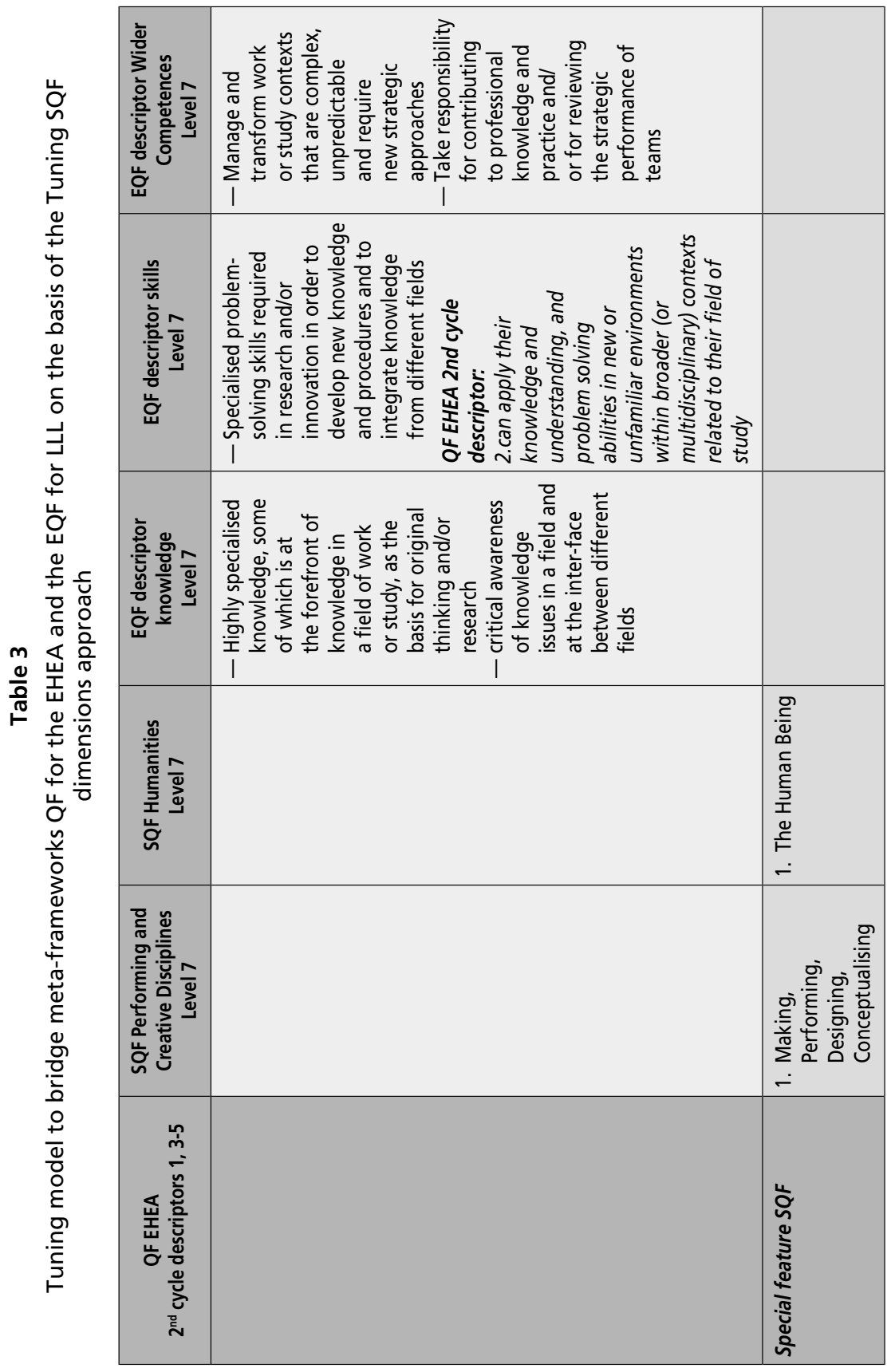




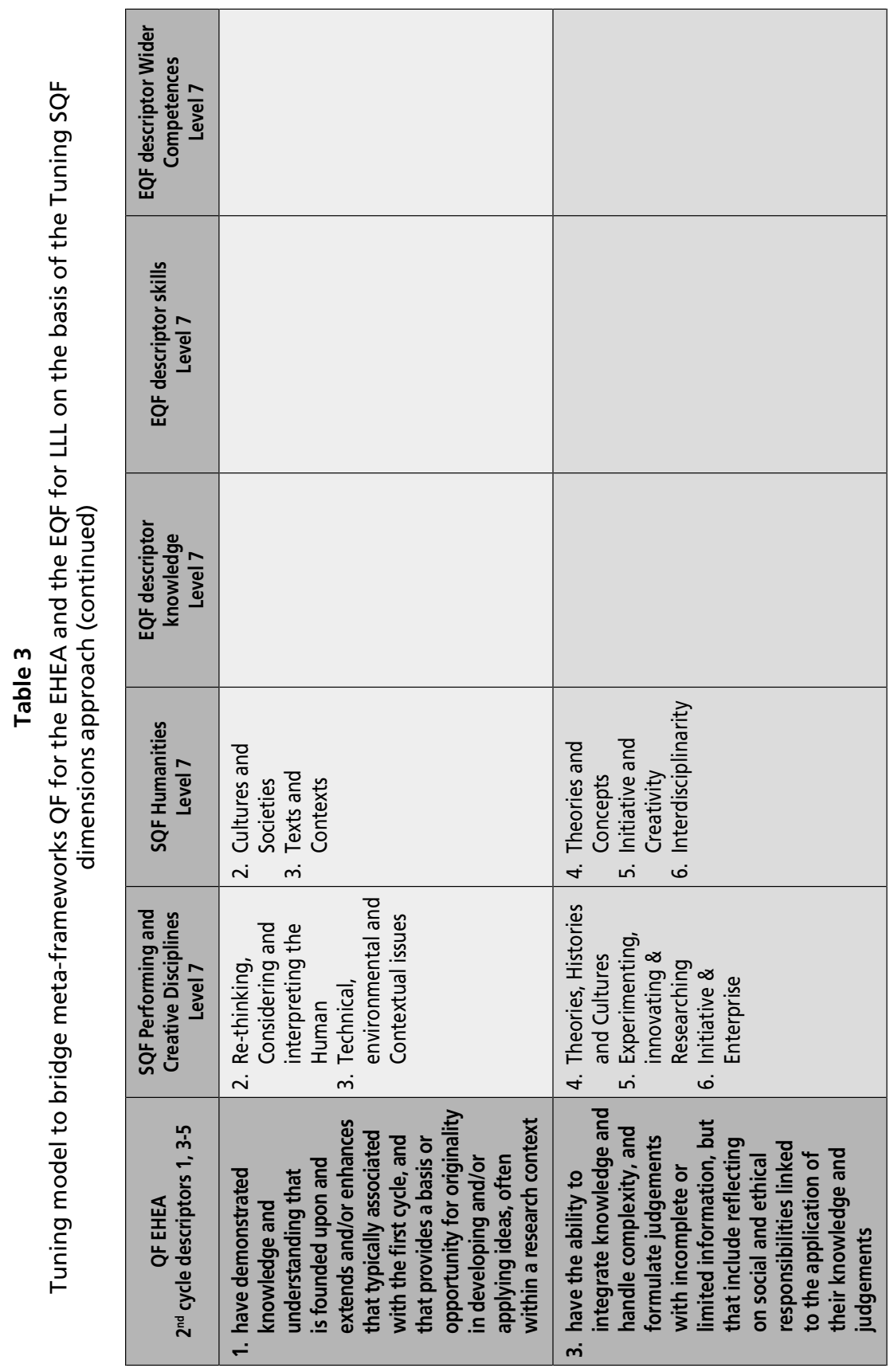




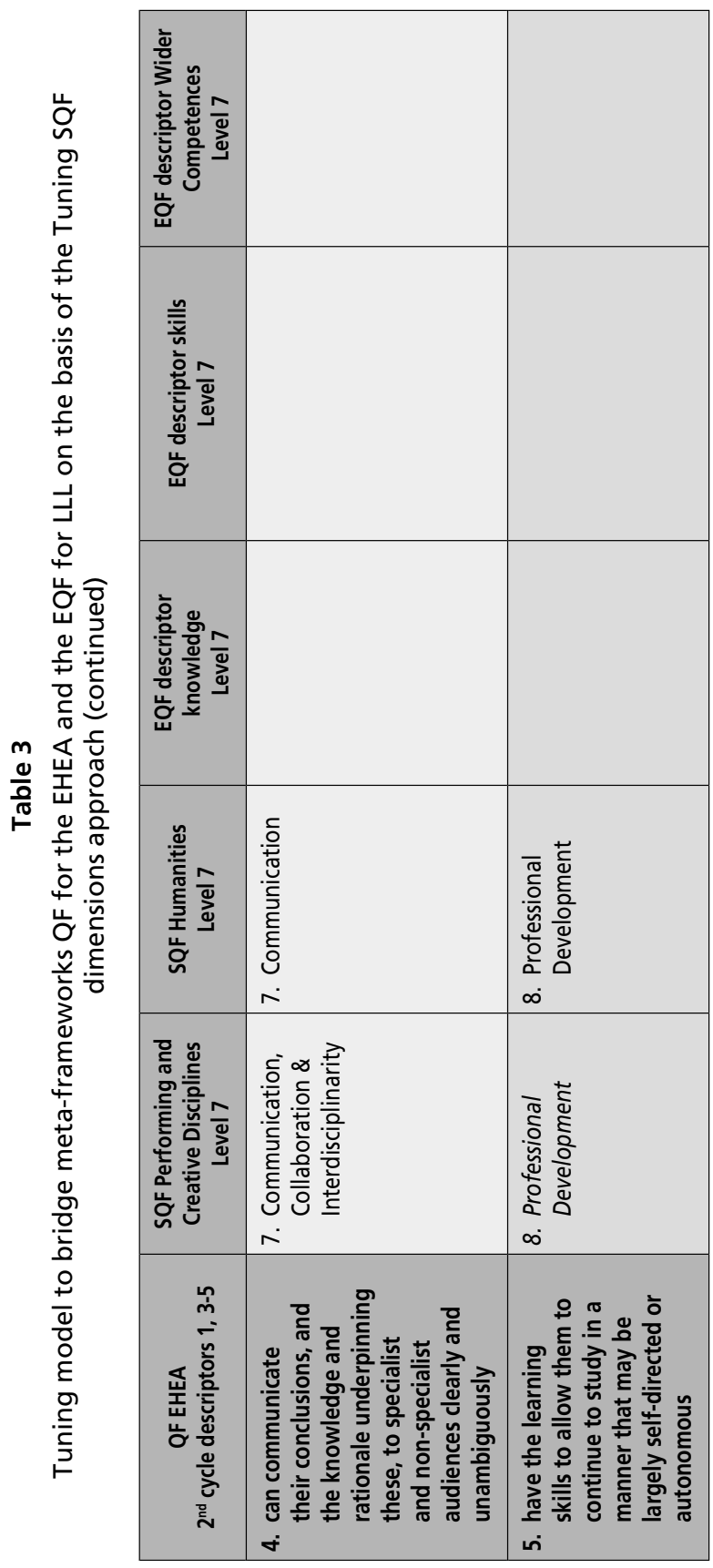


The result is a table which can be completed for each subject area, which results in a Meta profile for that particular academic field, such as music or linguistics. The profile and table can then be used as a basis for describing each degree programme according to the mission of an institution, department and the particular features in terms of its (tailored) programme learning outcomes.

By using this approach a transparent model is created, which is easy to operate and to understand by admissions and recognitions officers as well as by academics. This can be illustrated by filling in the table at the level of a degree programme. We use for this exercise the renowned Erasmus Mundus Master Course Euroculture. Europe in the Wider World. This is an interesting example, because Euroculture is not only a multi-dimensional programme, it is also clearly an inter disciplinary one. If the model is appropriate for such a complex programme, one might expect that it can be applied to all degree programmes. Although the programme is related to the sectors of Humanities as well as Social Sciences, its centre of gravity is located in the first sector. Using the Humanities dimensions seems, therefore, to be appropriate. The outcome is presented in table 4 .

\section{Conclusion}

It seems fair to conclude that during the last decade tremendous progress has been made in developing instruments, models and tools to accommodate the explosion of student mobility that has flooded Europe and the world.

As has been stipulated this progress is mainly due to the commitment of individual visionaries. Their ideas were institutionalized and supported by formal organizations at both national and international level.

When at the Bologna conference in Berlin the Ministers "encourage the member States to elaborate a framework of comparable and compatible qualifications for their higher education systems, which should seek to describe qualifications in terms of workload, level, learning outcomes, competences and profile" they initiated a fundamental shift from input or staff-centred learning to output or student-centred learning. With this announcement not only governments but also most higher education institutions obtained an assignment with far reaching consequences. Already from 2000-2001 on this process was prepared by the Joint Quality Initiative and the Tuning Projects and confirmed at the Amsterdam Bologna Seminar on Quality which resulted in the Amsterdam consensus. At that conference, the work of government, of quality assurance officials and academics represented in Tuning came together. 


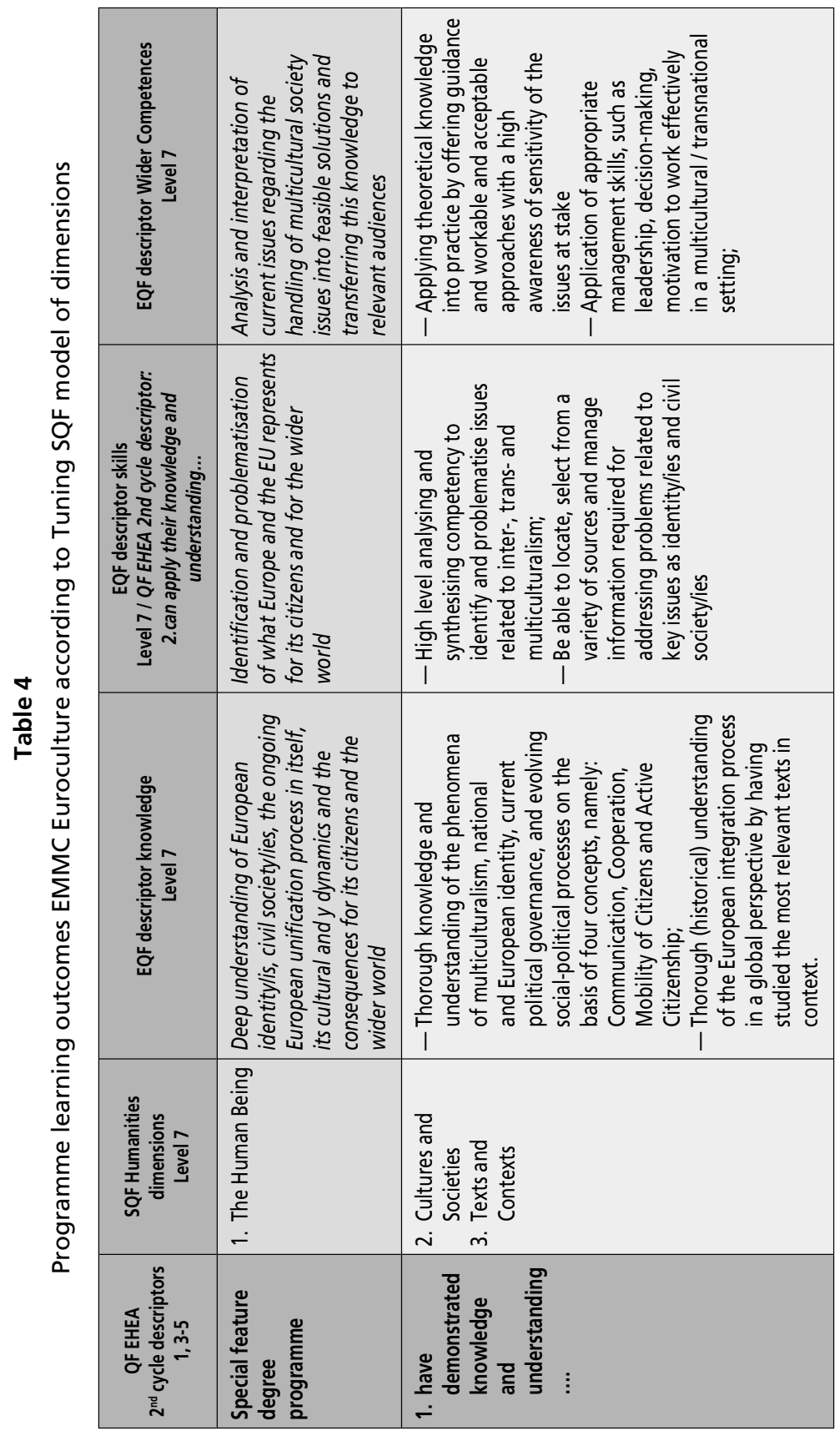




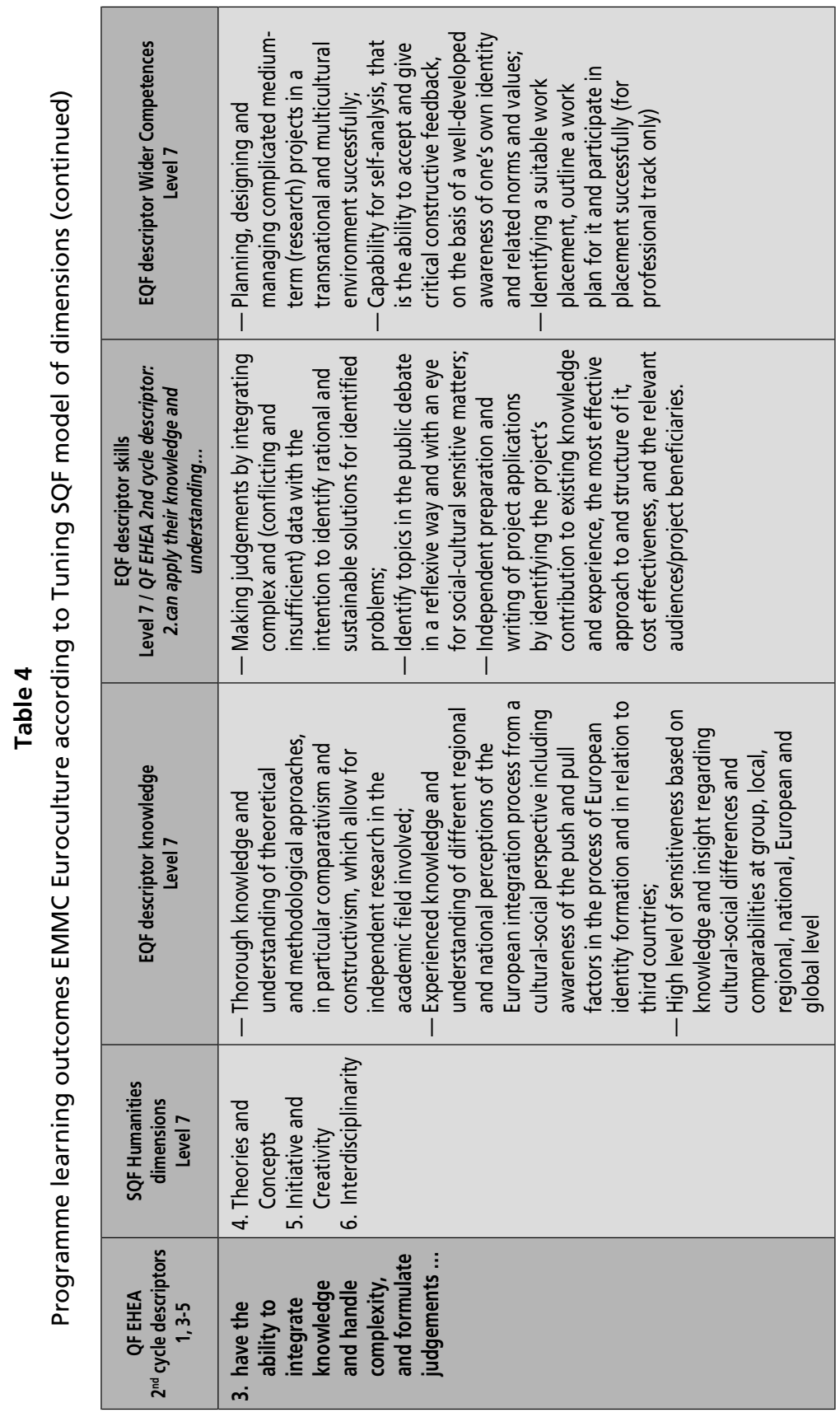




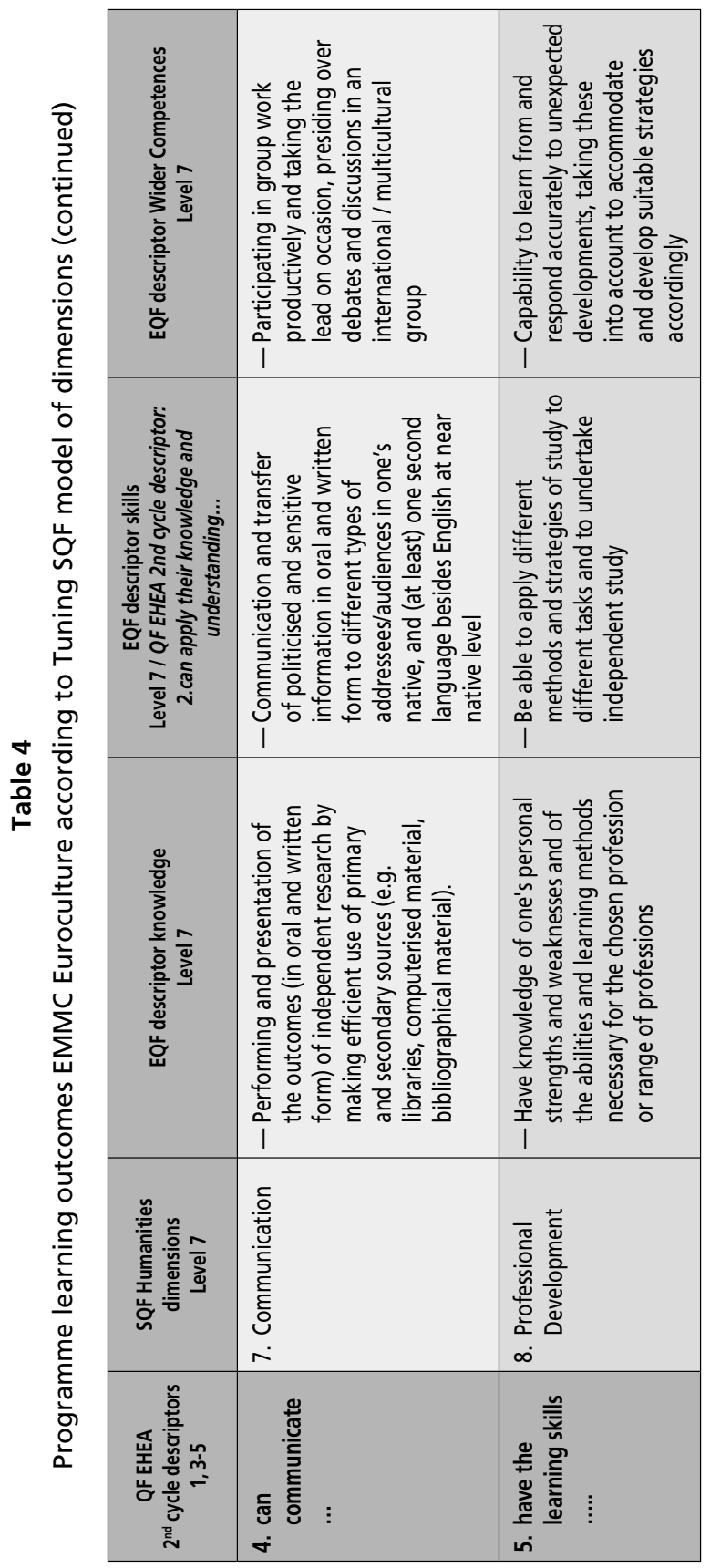


The Copenhagen Bologna seminar, which took place one year later, confirmed that frameworks and reference points would be an absolute necessity for developing a European Higher Education Area. The previous fifteen years had showed us that ETCS in its existing stage of being mainly a transfer system would be insufficient. In practice the unreliable mechanism of course-to-course comparison instead of comparing periods of study measured in ECTS credits was still widely used.

Therefore the central question posed in this article - whether qualifications frameworks, sectoral profiles or frameworks as well as degree programme profiles or reference points are indispensable instruments for national and international higher education in the world of today - can only be answered positively. Output-based learning can simply not work without clear reference points. It is a cause for praise that in the Bergen Communiqué (2005) the QF for EHEA based on work of the JQI which has resulted in the Dublin Descriptors, was endorsed. The European Commission deserves the same praise for the development of the EQF for LLL, which was agreed three years later by the Council of Ministers and the European Parliament. However, at the same time, it needs underlining that both meta-frameworks were developed by 'officials', not academics. It is therefore no surprise that both frameworks did not land or landed very slowly in the academic world. If accepted this was mainly due to the fact that it was built according to the quality assurance and accreditation criteria.

During the same years Tuning and Thematic networks developed their reference points for individual subject areas. This was a successful process the documents produced were well received - , but its application was very variable which was mainly due to the fact that it was left to the individual projects to distribute their results. This has proven to be a strategic mistake. Although since the Leuven Communique the ministers and their officials asked explicitly for the support of the higher education institutions, they have so far shown no serious interest in what has been developed as international mechanisms by the higher education sector to implement the outcomes based approach. This has clearly backfired on the Bologna Process as such. It has simply not been understood that degree programme reforms do not only require references at a meta-level, but most at all at the level of the individual subject area and the sector in which they have been positioned.

However, it is not too late. It has not been helpful that higher education institutions have had to deal with two competing European Qualifications frameworks - for more than 5 years now - frameworks which are not fully compatible. The development of Tuning sectoral frameworks based on dimensions seems to be a breakthrough. They not only bridge the two European meta-frameworks but also the meta-profiles / reference points at 
subject area level. The two sectoral frameworks or profiles developed so far offer the necessary precision which is required for degree programme design, delivery, quality assurance and enhancement and the recognition of degrees and periods of studies. Compatible frameworks should be rapidly developed for all other sectors. This might be the Columbus' Egg for which academic institutions and their academics have been looking: a simple, transparent instrument which is owned and used by all involved in the modernization of higher education in Europe and the world.

\section{Bibliography}

"Bologna Seminar on Qualification Structures in Higher Education in Europe. Recommendations." Copenhagen: Bologna-Berlin2003 Project Team, 2003. http://www.bologna-berlin2003.de/pdf/Results_copenhagen.pdf.

“Dublin Descriptors.” 2004. http://www.tcd.ie/vpcao/academic-development/assets/ pdf/dublin_descriptors.pdf.

"European Qualifications Framework (EQF).” 2008. http://ec.europa.eu/education/ lifelong-learning-policy/eqf_en.htm.

Bergan, Sjur. "Qualification Structures in European Higher Education." A report on the Danish Bologna Seminar, København, March 27 - 28, 2003. Strasbourg/ København: European Higher Education Area (EHEA), 2003. http://www .ehea. info/Uploads/Seminars/030327-28Report_General_Rapporteur.pdf.

Campbell, Carolyn, and Marijk van der Wende. "International Initiatives and Trends in Quality Assurance for European Higher Education. Exploratory Trend Report." Helsinki: European Network for Quality Assurance in Higher Education, 2000. http://www.enqa.eu/files/initiatives.pdf.

De Wit, Hans. "Internationalisation of Higher Education in Europe and Its Assessment, Trends and Issues." The Hague: Nederlands-Vlaamse Accreditatieorganisatie (Accreditation Organisation of the Netherlands and Flanders) - NVAO, 2010. http://nvao.com/page/downloads/Internationalisation_ of_Higher_Education_in_Europe_DEF_december_2010.pdf.

Erasmus Student Network (ESN). "Problems of Recognition in Making Erasmus 2010 (PRIME 2010). Final Report. Public Part.” Brussels: Audiovisual \& Culture Executive Agency, Education and Culture DG, European Commission, 2011. http://eacea.ec.europa.eu/llp/project_reports/documents/erasmus/ accompanying_measures_2010/era_am_177245.pdf.

European Ministers for Higher Education. "The Bologna Process 2020 - the European Higher Education Area in the New Decade: Communiqué of the Conference of European Ministers Responsible for Higher Education, Leuven and Louvain-La-Neuve, 28-29 April 2009 [ Leuven Communiqué].” 2009. http://www.ond.vlaanderen.be/hogeronderwijs/bologna/conference/documents/ leuven_louvain-la-neuve_communiqu\%C3\%A9_april_2009.pdf. 
. " 'Realising the European Higher Education Area': Communiqué of the Conference of Ministers Responsible for Higher Education in Berlin on 19 September 2003 [Berlin Communiqué].” Berlin: Bologna-Berlin2003 Project Team, 2003. http://www.bologna-berlin2003.de/pdf/Communique1.pdf

Harvey, Lee, and Diana Green. "Defining Quality." Assessment \& Evaluation in Higher Education 18, no. 1 (1993): 9-34.

Jeliazkova, Margarita, and Don F. Westerheijden. "Systematic Adaptation to a Changing Environment: Towards a Next Generation of Quality Assurance Models." Higher Education 44, no. 3-4 (2002 ): 433-48.

Knight, Jane, and Hans de Wit. Quality and Internationalisation of Higher Education. Paris: OECD Publishing, 1999.

Lokhoff, Jenneke, Bas Wegewijs, Katja Durkin, Robert Wagenaar, Julia González, Ann Katherine Isaacs, Luigi F. Donà dalle Rose, and Mary Gobbi, eds. A Tuning Guide to Formulating Degree Programme Profiles. Bilbao, Groningen, and The Hague: University of Deusto, 2010.

Quality Assurance Agency for Higher Education (QAA). http://www.qaa.ac.uk/.

_. "Subject Benchmark Statements. Statements Setting out What Achievement

Is Expected According to Level and Subject." http://www.qaa.ac.uk/ AssuringStandardsAndQuality/subject-guidance/Pages/Subject-benchmarkstatements.aspx.

Teichler, Ulrich. "Mutual Recognition and Credit Transfer in Europe: Experiences and Problems." Higher Education Forum 1, no. 2003 (2003): 33-53.

Tuning Educational Structures in Europe (Tuning Europe). http://www.unideusto. org/tuningeu/.

- Tuning Sectoral Qualifications Frameworks for the Humanities and the Arts. Final Report 2010 - 2011 [SQF HUMART Final Report 2010-2011]. Bilbao: University of Deusto, 2012.

_ . "Tuning SQF for the Social Sciences." http://www.unideusto.org/tuningeu/ tuning-sqf-social-sciences.html.

Van Damme, Dirk. "European Quality Assurance: Development and Challenges." Brussels: Steering Committee of Tuning Project, 2001.

—. "Internationalization and Quality Assurance: Towards Worldwide Accreditation?" Paper commissioned for the IAUP XIIth Triennial Conference, Brussels, 11-14 July 1999. http://citeseerx.ist.psu.edu/viewdoc/download?doi=1 0.1.1.199.5877\&rep=rep1\&type=pdf.

_. "Trends and Models in International Quality Assurance and Accreditation in Higher Education in Relation to Trade in Education Services." Paper presented at the OECD / US Forum on Trade in Educational Services, Washington, D.C., 23-24 May 2002. http://www.unizg.hr/fileadmin/upravljanjekvalitetom/pdf/ docsmjernice/oecd_trends_and_models.pdf.

Van der Wende, Marijk C. , and Don F. Westerheijden. "International Aspects of Quality Assurance with a Special Focus on European Higher Education." Quality in Higher Education 7, no. 3 (2001): 233-45.

Van Gaalen, Adinda. "Internationalisation and Quality Assurance "In EAIE Professional Development Series for International Educators, Volume 4. 
Amsterdam: European Association for International Education (EAIE), 2010. http://www .eaie.org/home/publishing/order-a-publication.html.

Van Vught, Frans A., and Don. F. Westerheijden. Quality Management and Quality Assurance in European Higher Education: Methods and Mechanisms. Luxembourg: Office for Official Publications of the Commission of the European Communities, 1993.

- "Towards a General Model of Quality Assessment in Higher Education." Higher Education 28, no. 3 (1994): 355-71.

Westerheyden, Don F., and Marlies Leegwater. "Working on the European Dimension of Quality. Report of the Conference on Quality Assurance in Higher Education as Part of the Bologna Process, Amsterdam, 12-13 March 2002." Zoetermeer: Ministry of Education, Culture and Sciences (The Netherlands), 2003. 